\title{
Short Communication \\ Somatic glypican 3 (GPC3) mutations in Wilms' tumour
}

\author{
GRM White', AM Kelsey², JM Varley' and JM Birch*,3 \\ 'Cancer Research UK Cancer Genetics Group, Paterson Institute for Cancer Research, Wilmslow Road, Manchester M20 4BX, UK; ${ }^{2}$ Department of \\ Histopathology, Royal Manchester Children's Hospital, Manchester M27 IHA, UK; ${ }^{3}$ Cancer Research UK Paediatric \& Familial Cancer Research Group, \\ Royal Manchester Children's Hospital, Manchester M27 4HA, UK
}

Tumour and normal tissue from $4 \mathrm{I}$ male cases of Wilms' tumour were screened to determine the presence of sequence variants in the glypican 3 (GPC3) gene. Two non-conservative single base changes were present in tumour tissue only. These findings imply a possible role for GPC3 in Wilms' tumour development.

British Journal of Cancer (2002) 86, 1920 - 1922. doi:10.1038/sj.bjc.66004I7 www.bjcancer.com

(c) 2002 Cancer Research UK

Keywords: Wilms' tumour; glypican 3; mutation

It has been known for many years that the risk of Wilm' tumour (WT) is greatly increased in children with certain congenital abnormalities and syndromes, but the complexity of WT genetics has only been recognised more recently (Hastie, 1994). Thus far the only WT gene to be fully characterised is WT1, located on chromosome $11 \mathrm{p} 13$ but deletion or mutation to WT1 is found in only about $20 \%$ of sporadic WT (Huff, 1998). Beckwith-Wiedemann syndrome (BWS) is characterised by pre-and/or post-natal overgrowth and a variety of other congenital abnormalities and confers a greatly increased risk of WT (DeBaun and Tucker, 1998). Other overgrowth syndromes may also predispose to WT. Numerically the most important of these is Simpson-GolabiBehmel syndrome (SGBS) which shows an X-linked pattern of inheritance. WT has been noted in a number of patients with SGBS (Xuan et al, 1994, 1999; Hughes-Benzie et al, 1996; Lindsay et al, 1997).

Constitutional deletions or mutations in the glypican 3 gene (GPC3) at Xq26 are found in many SGBS families (Pilia et al, 1996). This suggests that deletion or mutation in GPC3 may be involved in the development of some WT cases. The possibility that somatic mutations to GPC3 may be present in sporadic WT not associated with SGBS therefore also arises. To investigate this possibility we have analysed an unselected series of WT cases, for the presence of somatic and constitutional alterations to GPC3 in tumour and normal tissue respectively.

\section{MATERIALS AND METHODS}

Approval for the project was given by the relevant research ethics committees. Histopathological material from incident cases of WT included in the Manchester Children's Tumour Registry (Blair and Birch, 1994) was examined. Paraffin blocks containing tumour tissue and normal kidney respectively, were selected for each case. To simplify the analysis male cases only were included in the study.

One to two 10-micron sections from each block were placed in individual tubes and DNA extracted as described (Varley et al, 1999). Oligonucleotide primers were custom synthesised by Life

*Correspondence: Professor JM Birch; E-mail: Jillian.m.birch@man.ac.uk Received 30 November 200I; revised 17 April 2002; accepted 25 April 2002
Technologies to a standard purity. Table 1 details the main GPC3 primers used in this study. PCR reactions were carried out using a Techne GeneE Thermal Cycler. A standard protocol of $100 \mu 1$ reactions, containing $0.5 \mu \mathrm{g}$ of each primer, either $1 \times$ Taq buffer (Roche) or $1 \times$ TNK 100 buffer (Blanchard et al, 1993), $100 \mu \mathrm{M}$ dNTPs and 3 units of Taq polymerase, with or without 5\% DMSO, was run for one cycle at $94^{\circ} \mathrm{C}$ for $3 \mathrm{~min}$, followed by 38 cycles of $94^{\circ} \mathrm{C}$ for $1 \mathrm{~min}$, annealing temperature (see Table 2) for $1 \mathrm{~min}$, and $72^{\circ} \mathrm{C}$ for $1 \mathrm{~min}$. A final extension at $72^{\circ} \mathrm{C}$ for $10 \mathrm{~min}$ was given at the end of the last cycle. Products from the same PCR reaction could be used for both SSCP analysis and subsequent sequencing.

Table 2 shows the primer pairs used for SSCP, providing total coverage of the coding region of GPC3. One $\mu 1$ of PCR product was subjected to a second round of amplification in a $10 \mu 1$ reaction $\left(10\right.$ cycles at $94^{\circ} \mathrm{C}$ for $1 \mathrm{~min}, 50^{\circ} \mathrm{C}$ for $1 \mathrm{~min}$, and $72^{\circ} \mathrm{C}$ for $1 \mathrm{~min}$ with the final cycle having an extension time of $10 \mathrm{~min}$ ) as described previously (Varley et al, 1999). Initially, tumour material only was examined. Where a variant was identified DNA from the corresponding normal tissue was analysed and the fragment sequenced. Controls (no DNA and normal DNA) were included on every gel. Any samples showing abnormal band shifts were re-analysed by repeating both first- and second-round SSCPPCR reactions.

PCR products were purified using a Wizard PCR Preps DNA Purification System (Promega). Approximately $100 \mathrm{ng}$ of this DNA was labelled with Big Dye Terminator DNA Sequencing Kit (ABI) using a Perkin Elmer 480 DNA Thermal Cycler and ABI protocols and sequenced using an ABI 377 system. The splice site prediction program made available from the Berkeley Drosophila genome project (http://www.fruitfly.org/seq_tools/splice.html) was applied routinely with any sequence variant to address the possibility of a new splice site being created.

\section{RESULTS}

Paired tumour and normal tissue samples were available on 41 male cases. Seven different variants were detected. Variant 4 was present in three cases but the remaining six variants were detected in single cases only. Variants 1-5 were present in both tumour derived and the corresponding normal DNA. Variants 6 and 7 were detected in tumour derived material only (Figure 1). 
$138 \mathrm{~N}$

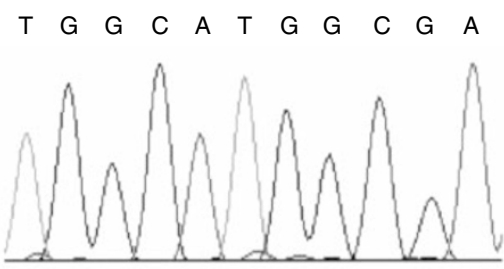

$\Uparrow$
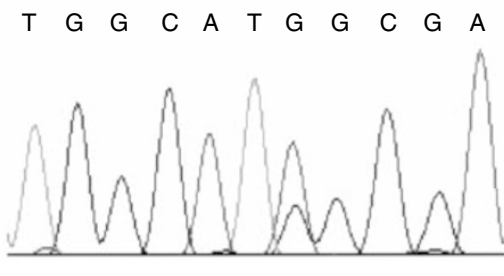

$527 \mathrm{~N}$

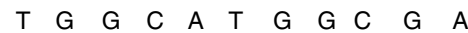

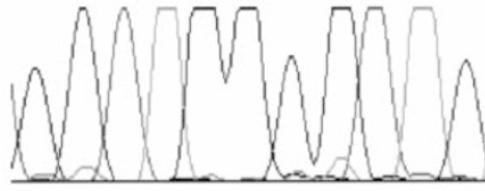

ঐ

T $\quad G \quad G \quad C \quad C \quad A \quad T \quad G \quad G \quad C \quad G \quad A$

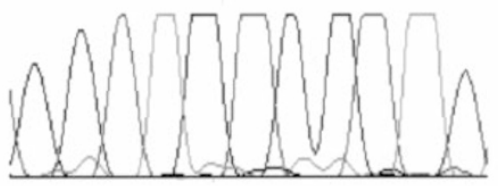

527T Variant 7

Figure I Sequencing electropherograms of variants 6 and 7. Sample 138 shows a $C-T$ transition, not present in the normal, which changes a basic histidine to an uncharged polar tyrosine at position 558. The variant in sample 527 is a G-A transition at position 1902 which changes the non-polar alanine to the polar threonine. Note that sample 138 is shown sequenced on the reverse strand.

Table I Glypican 3 (GPC3) oligonucleotides used in this study

\begin{tabular}{|c|c|c|}
\hline Exon & Primer & Sequence \\
\hline \multirow[t]{2}{*}{ I } & IB* & 5’TAGGCACGCTCAAGGGAC \\
\hline & IF & 5'TCCTAGCTCCCTGCGAAGCA \\
\hline \multirow[t]{2}{*}{2} & $2 A^{*}$ & 5'GTTTGCCCTGTTTGCCATG \\
\hline & $2 B^{*}$ & 5'CAAATAATGATGCCACTAAGC \\
\hline \multirow[t]{10}{*}{3} & $3 A^{*}$ & 5'GGATTITCATGCTITAATTTG \\
\hline & $3 B^{*}$ & 5'AGGTCACGTCTTGCTCCTC \\
\hline & $3 C^{*}$ & 5'CCTGCCTGATTCAGCCTTGGAC \\
\hline & 3D* & 5'GTTGAAAAGAGACCAAGC \\
\hline & $3 \mathrm{E}^{*}$ & 5'GAGAGAATACATTCTGTCC \\
\hline & $3 \mathrm{~F}^{*}$ & 5'CCTCTGACAACTGTAGAC \\
\hline & $3 G$ & 5'CCTGAAGTTCAGTAAGGACTG \\
\hline & $3 \mathrm{H}$ & 5'ACCATCATCAGTCCCTGGCA \\
\hline & 3) & 5'ATGTAGAGAGCACATCTGTGA \\
\hline & $3 \mathrm{~K}$ & 5'CAAGCCTGACTCCACAAGCT \\
\hline \multirow[t]{2}{*}{4} & 4C & 5'CTATCATATCTGCACAAGTATC \\
\hline & $4 \mathrm{D}$ & 5'CAATTGTTAATTGTATTGTGGAAT \\
\hline \multirow[t]{2}{*}{5} & $5 A^{*}$ & 5'GCCTCTTATGCACAGATG \\
\hline & $5 D$ & 5'CCTCAAATATTGCTATATGTAAC \\
\hline \multirow[t]{2}{*}{6} & $6 C$ & 5’TGAGCTTGTGGTCAGTCTGA \\
\hline & 6D & 5'TCCTCTCTCTCGGTTATTTCTAC \\
\hline \multirow[t]{2}{*}{7} & $7 A^{*}$ & 5'GAAGAGCTGATGCATTCC \\
\hline & 7C & 5'CATTTGGGTCAGCACTAATCAG \\
\hline \multirow[t]{2}{*}{8} & $8 A^{*}$ & 5'GTGTTATACTGAGGCTATG \\
\hline & $8 \mathrm{G}$ & 5'GTGGTTCCCTTTATCGAGGA \\
\hline
\end{tabular}

Some denoted as * have been described previously (Huber et al, 1997). More detailed sequence information is available with GenBank accession numbers AF003529, Z99570, AL009I74, AL0087I2 and AC002420.

Variants 1 and 3 were present in the same case. Variant 1 is due to a silent $\mathrm{T}-\mathrm{C}$ transition in exon 7, position 1697 (all nucleotide numbering refers to the sequence described by Huber et al, 1997). Variant 3 is due to a silent $A-G$ transition in exon 8 position 1823. Both variants were reported in three out of 13 ovarian cancer cell lines, and always occur together (Lin et al, 1999). Variant 2 is the result of a G-A transition in exon 5, position 1482, which changes non-polar valine to non-polar methionine. We have observed the same sequence variant in blood samples from two
Table 2 Details of the main primer pairs and PCR conditions used to provide total coverage of the coding region of GPC3 for SCCP analysis

\begin{tabular}{|c|c|c|c|c|c|}
\hline Exon & Primer pair & Buffer & $\begin{array}{l}\text { DMSO } \\
( \pm 5 \%)\end{array}$ & $\begin{array}{l}\text { Annealing } \\
\text { temp ( } \mathrm{C})\end{array}$ & $\begin{array}{l}\text { Product } \\
\text { size (bp) }\end{array}$ \\
\hline | & $\mathrm{IB} / \mathrm{IF}$ & Roche & + & 60 & 225 \\
\hline 2 & $2 \mathrm{~A} / 2 \mathrm{~B}$ & Roche & - & 60 & 329 \\
\hline \multirow[t]{5}{*}{3} & 3A/3J & Roche & - & 59 & 183 \\
\hline & $3 \mathrm{~K} / 3 \mathrm{~B}$ & Roche & + & 60 & 211 \\
\hline & $3 \mathrm{C} / 3 \mathrm{H}$ & TNKIOO & - & 55 & 255 \\
\hline & $3 G / 3 D$ & Roche & - & 58 & 243 \\
\hline & $3 \mathrm{E} / 3 \mathrm{~F}$ & Roche & - & 55 & 173 \\
\hline 4 & $4 C / 4 D$ & TNKIOO & - & 57 & 231 \\
\hline 5 & 5A/5D & Roche & - & 57 & 200 \\
\hline 6 & $6 C / 6 D$ & Roche & - & 60 & 279 \\
\hline 7 & 7A/7C & Roche & + & 59 & 221 \\
\hline 8 & $8 \mathrm{~A} / 8 \mathrm{G}$ & Roche & - & 60 & 296 \\
\hline
\end{tabular}

out of 36 unselected breast cancer patients (i.e. $72 \mathrm{X}$ chromosomes). Variants 4 and 5 are the result of the reduction in a run of 16 Ts in the splice acceptor region of exon 3-15 and 14 respectively. We consider variants $1-5$ to be polymorphisms with no predicted effect on splicing.

Sequencing showed variant 6 to be due to a $\mathrm{C}-\mathrm{T}$ transition in exon 3 position 558. This changes a basic histidine to an uncharged polar tyrosine. Variant 7 is due to a G-A transition in exon 8, position 1902. This changes the non-polar alanine to the polar threonine. Variants 6 and 7 are tumour specific i.e. they were present in tumour DNA but were not detected in DNA from normal kidney and may represent somatic mutations.

\section{DISCUSSION}

GPC3 is one of six glypican genes which so far have been identified in vertebrates. Glypicans are highly evolutionarily conserved cell surface proteins which have a role in morphogenesis and growth regulation. Glypican 3, encoded by the GPC3 gene, is a GPI-linked heparan sulphate proteoglycan. It is highly expressed in embryonic mesodermal tissues corresponding to the tissues showing over- 
growth or other abnormalities in SGBS (Selleck, 2000; De Cat and David, 2001). It is the only glypican to date for which mutations in humans have been documented.

We have detected somatic point mutations in the GPC3 gene in two out of $41 \mathrm{WT}$ cases (4.9\%). This represents the first fully documented report of such mutations in tumour tissue and provides evidence that disruption of the GPC3 protein may be involved in initiation, development or progression in some Wilms' tumours. Support for such a role is provided by the observation that GPC3 is expressed in WT tissue but not in the corresponding normal kidney (Saikali et al, 2000). The 4.9\% GPC3 mutation frequency detected in the present series may be an underestimate since the methods used did not include analysis of the promoter region and would not have detected large deletions of GPC3 exons which occur in some SGBS patients (Hughes-Benzie et al, 1996; Pilia et al, 1996; Lindsay et al, 1997). Southern blotting is not suitable for the archival material available to us, but we have partially addressed this issue by carrying out multiplex PCR analysis of GPC3 exons and a control gene for 20 of the WT samples. Results (data not shown) showed no evidence for deletions.

The mutation in exon 8 occurs near to the $\mathrm{C}$ terminus in a predicted region of glycosylphosphatidylinositol (GPI) anchorage. A number of deletions detected in patients with SGBS also affect exon 8 and probably prevent attachment of any product to the cell membrane (Hughes-Benzie et al, 1996; Pilia et al, 1996; Lindsay et

\section{REFERENCES}

Blair V, Birch, JM (1994) Patterns and temporal trends in the incidence of malignant disease in children: II solid tumours of childhood. Eur J Cancer 30A: $1498-1511$

Blanchard MM, Taillon-Miller P, Nowotny P, Nowotny V (1993) PCR buffer optimization with uniform temperature regimen to facilitate automation. PCR Methods and Applications 2: $234-240$

DeBaun MR, Tucker MA (1998) Risk of cancer during the first four years of life in children from the Beckwith-Wiedemann Syndrome registry. I Pediatr 132: $398-400$

De Cat B, David G (2001) Developmental roles of the glypicans. Semin Cell Dev Biol 12: $117-125$

Gonzalez AD, Kaya M, Shi W, Song H, Testa JR, Penn LZ, Filmus J (1998) OCI-5/GPC3, a glypican encoded by a gene that is mutated in the Simpson-Golabi-Behmel overgrowth syndrome, induces apoptosis in a cell line-specific manner. J Cell Biol 141: 1407-1414

Hastie ND (1994) The genetics of Wilms' tumor - a case of disrupted development. Annu Rev Genet 28: 523-558

Huber R, Crisponi L, Mazzarella R, Chen C-N, Su Y, Shizuya H, Chen EY, Cao A, Pilia G (1997) Analysis of exon/intron structure and $400 \mathrm{~kb}$ of genomic sequence surrounding the $5^{\prime}$-promoter and $3^{\prime}$-terminal ends of the human glypican 3 (GPC3) gene. Genomics 45: 48-58

Huff V (1998) Wilms' Tumor Genetics. Am J Med Genet 79: 260 - 267

Hughes-Benzie RM, Pilia G, Xuan JY, Hunter AGW, Chen E, Golabi M, Hurst JA, Kobori J, Marymee K, Pagon RA. (1996) Simpson-GolabiBehmel Syndrome: genotype/phenotype analysis of 18 Affected males from 7 unrelated families. Am J Med Genet 66: 227-234 al, 1997). Furthermore, the GPI-anchoring domain has been identified as critical for the induction of apoptosis in mesothelioma and breast cancer cell lines (Gonzalez et al, 1998). The mutation in exon 3 does not appear to be in any known functional domain but is non-conservative and may be expected to affect protein conformation. The five published cases of WT in patients with SGBS in whom alterations in the GPC3 gene have been detected were all associated with constitutional deletions in exon 1 and/or exon 2 (Hughes-Benzie et al, 1996; Pilia et al, 1996; Lindsay et al, 1997). Additional studies are required to establish the functional consequences of these putative somatic mutations.

In conclusion in this preliminary study, we have identified somatic mutations in the GPC3 gene in two of 41 cases of WT, providing evidence of a link between developmental genes and embryonal tumours. Further investigations of the possible role of GPC3 in WT are indicated.

\section{ACKNOWLEDGEMENTS}

We thank Professor John Gallagher for helpful discussion. This work was funded by Cancer Research UK. Jillian M Birch is a Cancer Research UK Professorial Fellow.
Lindsay S, Ireland M, O’Brien O, Clayton-Smith J, Hurst JA, Mann J, Cole T, Sampson J, Slaney S, Schlessinger D, Burn J, Pilia G (1997) Large scale deletions in the GPC3 gene may account for a minority of cases of Simpson-Golabi-Behmel syndrome. J Med Genet 34: 480-483

Lin H, Huber R, Schlessinger D, Morin PJ (1999) Frequent silencing of the GPC3 gene in ovarian cancer cell lines. Cancer Res 59: 807-810

Pilia G, Hughes-Benzie RM, MacKenzie A, Baybayan P, Chen EY, Huber R, Neri G, Cao A, Forabosco A, Schlessinger D (1996) Mutations in GPC3, a glypican gene, cause the Simpson-Golabi-Behmel overgrowth syndrome. Nature Genet 12: $241-247$

Saikali Z, Sinnett, D. (2000) Expression of glypican 3 (GPC3) in embryonal tumors. Int J Cancer 89: 418-422

Selleck SB (2000) Proteoglycans and pattern formation, sugar biochemistry meets developmental genetics. TIGS 16: $206-212$

Varley JM, McGown G, Thorncroft M, James LA, Margison GP, Forster G, Evans DGR, Harris M, Kelsey A, Birch JM (1999) Are there low penetrance TP53 alleles? Evidence from childhood adrenocortical tumors. Am J Hum Genet 65: 995-1006

Xuan JY, Besnar A, Ireland M, Hughes-Benzie RM, MacKenzie AE (1994) Mapping of Simpson-Golabi-Behmel syndrome to Xq25-q27. Hum Mol Genet 3: $133-137$

Xuan JY, Hughes-Benzie RM, MacKenzie AE (1999) A small interstitial deletion in the GPC3 gene causes Simpson-Golabi-Behmel syndrome in a Dutch-Canadian family. J Med Genet 36: 57-58 